\title{
Airway management practices in COVID ICU during the first and second phases of the pandemic: our experience
}

\author{
Nazia Nazir, MD ${ }^{1} \triangle$, Anupriya Saxena, MD ${ }^{2} \triangle$ \\ Author affiliations: \\ 1. Associate Professor; 2. Assistant Professor \\ Department of Anaesthesiology, Government Institute of Medical Sciences, Uttar Pradesh. \\ Correspondence: Dr. Nazia Nazir; Phon e: +91 9560102957; E-mail: nazunazir@gmail.com
}

Key words: Airway management; COVID-19; Pandemic; Intensive care

Citation: Nazir N, Saxena A. Airway management practices in COVID ICU during the first and second phases of the pandemic: our experience. . Anaesth. pain intensive care 2021;25(6):834-835; DOI: 10.35975/apic.v25i6.1716

Various airway management devices and techniques have been revised and recommended to be used in COVID patients. ${ }^{1}$ In India, during the first wave (April 2020 to November 2020) ${ }^{2}$ the intubation strategy included: consultant-led intubation teams, the use of video laryngoscope (VL) and aerosol box (AB). ${ }^{3}$ During the second wave (April 2021 to June 2021), ${ }^{2}$ the intubation procedures were modified according to the availability of the resources, manpower, and some experience gained from the first wave.

This retrospective survey aimed to compare the intubation practice in the ICU of our hospital during the first and second waves of COVID. All adult patients with respiratory failure secondary to COVID, requiring endotracheal intubation (ETI) in ICU were included. Parameters compared were: seniority of the intubator (experience $>5 \mathrm{y}$ ), first attempt success rate (successful attempt: correct ETT placement confirmed by chest movement, capnography, and expired tidal volume of more than $8 \mathrm{ml} / \mathrm{kg}$. Unsuccessful attempt: failure of insertion of ETT under vision, no chest movement and no capnography trace on ventilation, or time $>60 \mathrm{sec}$, desaturation during ETI $\left(\mathrm{SpO}_{2}<90 \%\right)$. Use of VL (King Vision ${ }^{\circledR}$ VL) and AB (by Lai, Hsien Yung; 2020) was recorded.

Data were retrospectively collected from the patients' medical records for comparison (intubation notes). Eighty intubations were performed during the first wave and 264 during the second wave in our ICU. Using desaturation during ETI as a surrogate marker for the airway event, potential predictors of desaturation were

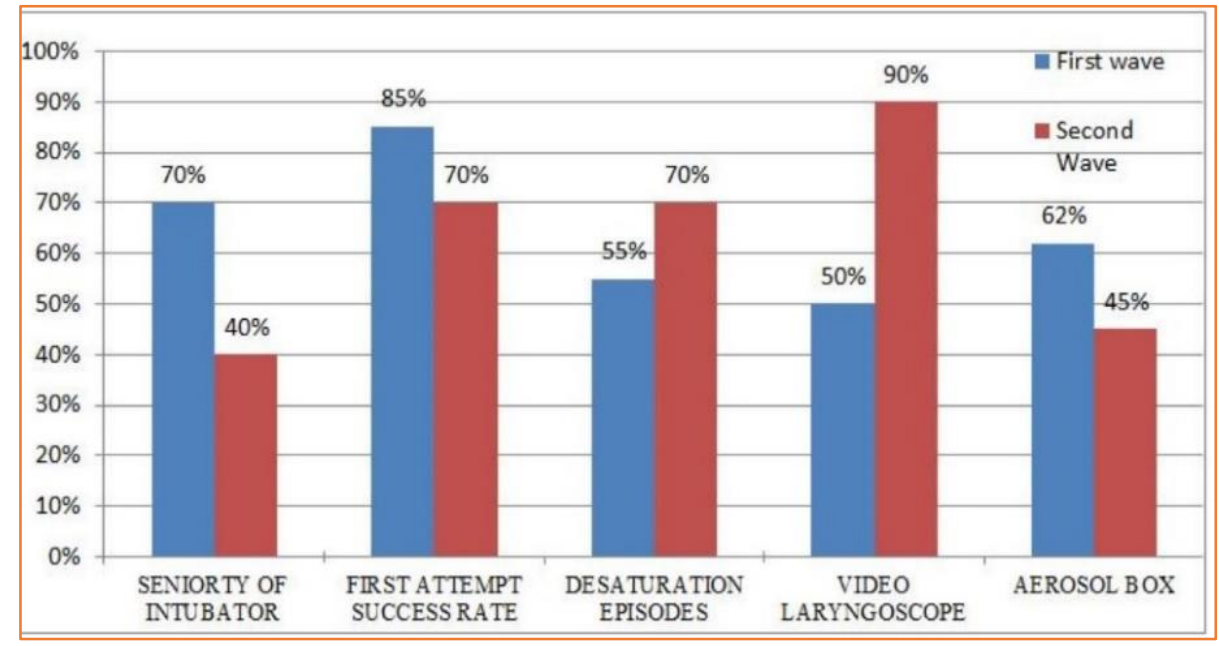

\section{Figure 1: Comparison of airway management in two COVID waves}

cohorts is shown in Figure 1.

1. Team composition: Senior faculty was predominantly the primary intubator during the first wave as compared to the second one (70\% vs. $40 \%)$. The increased participation of junior doctors as primary intubators was due to the massive surge in the number of COVID patients in the second wave of the pandemic.

2. The first attempt success rate for ETI was higher in the first wave $(85 \%$ vs. $70 \%)$. The increased number of attempts with higher desaturation episodes were observed in the second wave ( $70 \%$ vs $55 \%$ ), which could be due to the lesser experience of the junior ranked intubators, increased disease severity, and longer duration of NIV support before ETI. 
3. Use of $\mathrm{VL}$ was increased in the second phase (90\% vs. $50 \%$ ) Though the use of VL showed some promise when used effectively, most of the intubators during the first wave did not utilize this modality. This could be due to the lack of experience and familiarity with VL. Extensive airway education programs were undertaken in our institute between the two waves of pandemic which increased its use in the second wave.

4. Use of an $\mathrm{AB}$ was reduced in the second wave (from $62 \%$ to $30 \%$ ) as its use increased the difficulty as well as the time to successful intubation. A meta-analysis by Lim et al. also concluded that intubation time was significantly more with $\mathrm{AB} .^{4}$

This comparison aims to review and refine our airway management practices. This survey throws light on the importance of ongoing training programs and simulation workshops on airway management, to improve the skill level of the healthcare professionals. Advancement in skills can improve the outcome trajectory of the critically ill patients.

\section{References}

1. Orser BA. Recommendations for endotracheal intubation of covid-19 patients. Anesth Analg. 2020 May;130(5):1109-1110. [PubMed] DOI: 10.1213/ANE.0000000000004803

2. Kar SK, Ransing R, Arafat SMY, Menon V. Second wave of COVID-19 pandemic in India: Barriers to effective governmental response. EClinicalMedicine. 2021 Jun;36:100915. [PubMed] DOI: 10.1016/j.eclinm.2021.100915

3. Cook TM, El-Boghdadly K, McGuire B, McNarry AF, Patel A, Higgs $A$. Consensus guidelines for managing the airway in patients with COVID-19: Guidelines from the Difficult Airway Society, the Association of Anaesthetists the Intensive Care Society, the Faculty of Intensive Care Medicine and the Royal College of Anaesthetists. Anaesthesia. 2020 Jun;75(6):785799. [PubMed] DOI: $10.1111 /$ anae. 15054

4. Lim ZJ, Ponnapa Reddy M, Karalapillai D, Shekar K, Subramaniam A. Impact of an aerosol box on time to tracheal intubation: systematic review and meta-analysis. $\mathrm{Br} \mathrm{J}$ Anaesth. 2021 Mar;126(3):e122-e125. [PubMed] DOI: $\underline{10.1016 / \text { j.bja.2020.1 }}$ 